\title{
Long-Term Survival After Carpentier-Edwards Perimount Aortic Valve Replacement in Denmark: A Multi-Centre Observational Study
}

\section{Lytfi Krasniqi ( $\sim$ Lytfi.Krasniqi@rsyd.dk)}

Odense Universitetshospital https://orcid.org/0000-0002-8048-9779

Mads Philip Kronby

Department of Cardiac, Thoracic and Vascular Surgery, Odense University Hospital, Odense

Lars Peter Schødt Riber

Department of Cardiac, Thoracic and Vascular Surgery, Odense University Hospital, Odense

Research article

Keywords: Aortic valve replacement, Carpentier-Edwards Perimount, Long-term survival

Posted Date: June 17th, 2020

DOI: https://doi.org/10.21203/rs.3.rs-35599/v1

License: (a) (i) This work is licensed under a Creative Commons Attribution 4.0 International License. Read Full License 


\section{Abstract}

Background: This study describes the long-term survival, risk of reoperation and clinical outcomes for patients undergoing solitary surgical aortic valve replacement (SAVR) with a Carpentier-Edwards Perimount (CE-P) bioprosthetic in Denmark. The renewed interest in SAVR is based on the questioning regarding the long-term survival since new aortic replacement technique such as transcatheter aorticvalve replacement (TAVR) probably have shorter durability, why assessment of long-term survival could be a key issue for patients.

Methods: From November 1999 to November 2015 a cohort of a total of 1604 patients aged 20-91 undergoing solitary SAVR with CE-P in Western Denmark was obtained November 2018 from the Western Danish Heart Registry (WDHR). The primary endpoint was long-term survival from all-cause mortality. Secondary endpoints were survival free from major adverse cardiovascular and cerebral events (MACCE), risk of reoperation, cause of late death, patient-prothesis mismatch, risk of AMI, stroke, pacemaker or ICD implantation and postoperative atrial fibrillation (POAF). Time-to event analysis was performed with Kaplan-Meier curve, cumulative incidence function was performed with Nelson-Aalen cumulative hazard estimates. Cox regression was applied to detect risk factors for death and reoperation.

Results: In-hospital mortality was $2.7 \%$ and 30 -day mortality at $3.4 \%$. The $5-, 10$ - and 15 -year survival from all-cause mortality was $77 \%, 52 \%$ and $24 \%$, respectively. Survival without MACCE was $80 \%$ after 10 years. Significant risk factors of mortality were small valves, smoking and EuroSCORE II $\geq 4 \%$. The risk of reoperation was $<5 \%$ after 7.5 years and significant risk factors were valve prosthesis-patient mismatch and EuroSCORE II $\geq 4 \%$.

Conclusions: Patients operated with for aortic valve replacement with a Carpentier-Edwards Perimount valve shows a very satisfying long-term survival. Future research should aim to investigate biological valves long-term durability for comparison of different SAVR to different TAVR in long perspective.

\section{Background}

Aortic stenosis (AS) is the most frequent primary valve disease in Europe and North America (1). Surgical intervention remains the gold standard in treating the condition(2). Surgical aortic valve replacement (SAVR) with bioprosthetic is in Europe usually offered to patients older than 65 years of age with severe AS or severe aortic valve regurgitation and suitable for surgery, though it also is considered in patients younger than 65 years of age, depending on life expectancy, comorbidity, compliance and patient preference (1).

The greatest weakness of bioprosthetic valves are their limited durability, as they all in time are subject to structural valve deterioration (SVD) with calcification, pannus formation, cusp tears, or flail and non-SVD as regurgitation, prosthesis malposition, patient-prosthesis mismatch, late embolization, and prosthetic endocarditis (1,3-7). The rate of SVD correlates with age and the valves degenerate faster in younger patients $(1,6,8-10)$. Patients operated with SAVR have several risks of postoperative complications (11) 
including, but not limited to, acute renal failure $(12,13)$, major life-threatening bleeding $(12,14,15)$, permanent pacemaker (12-15), postoperative atrial fibrillation (POAF) (12, 16-18) and stroke (12-14). The operative mortality of SAVR is estimated between $2.8 \%$ and $4 \%(1,9,14,19)$. The Carpentier-Edwards Perimount (CE-P) (Edwards Lifesciences, Irvine, CA, USA) valve was introduced in Denmark 1999 and is now the preferred valve in multiple centres due to very satisfying manufacture-related durability (19).

The future application of SAVR is however being questioned, due to the technological advancement of transcatheter aortic-valve replacement (TAVR) (20). The primary objective of this registry-based retrospective cohort study is to investigate the long-term survival of all patients who underwent a solitary SAVR with CE-P valve bioprosthesis and secondary to explore the adverse clinical outcomes.

\section{Methods}

This registry-based study was approved by the Region Southern Denmark Data Protection Agency, Odense, Denmark, and the study followed the Strengthening the Reporting of Observational Studies in Epidemiology (STROBE) reporting guideline.

We conducted a population-based retrospective cohort study analysis including all patients who underwent solitary SAVR with CE-P valve in Western Denmark based on data from November 1999 to November 2015. The primary endpoint of this study was long-term survival from all-cause mortality with valve size 19 to $29 \mathrm{~mm}$ in comparison with the Danish background population. Secondary endpoints were survival from major adverse cardiovascular and cerebral events (MACCE), risk of reoperation, cause of late death, valve patient-prothesis mismatch (VP-PM), PAOF, risk of AMI, stroke and pacemaker. We excluded patients operated with other valve types of aortic valve replacement (AVR) or had concomitant surgery.

The data was obtained November 2018 from the Western Danish Heart Registry (WDHR), The National Danish Patient Registry and the Program of clinical quality development of the Danish Regions. WDHR is a multi-centre prospective registry and is the most comprehensive registry regarding AVR in Denmark. The background population was obtained from Statistics Denmark and matched according to our cohort with a mean age of 73 years and a follow-up of 15 years. MACCE is defined as all-time cardiovascular events and early ( $\leq 30$ days) cerebrovascular disease. Low-risk patients was defined according to guidelines, EuroSCORE II $<4 \%$ (1). VP-PM was evaluated as effective orifice area index (EOAl) $<0.85 \mathrm{~cm}^{2} / \mathrm{m}^{2}$ estimated with manufactural effective orifice area (EOA) measurements indexed with perioperative body surface area (BSA) knowing that the measurements reliability to predict EOAI are questioned. A total of 1613 people were registered with solitary SAVR in WDHR (figure 1). Six patients were duplicates, so the first surgery where kept, and the late will be included as reoperation. Three patients were removed due to invalid or inactive social security number. That leaves a population of 1604 patients whom all had an efficient follow-up.

Baseline characteristics were described using means, range and standard deviations for continuous variables and proportions for categorical variables. Time-to-death was calculated as the time in years 
from the date of operation to the time of death from all-cause or MACCE-cause. Survival was performed with the use of Kaplan-Meier estimates. The overall survival curve was compared to the background population graphicly by evaluating overlap of curves and confidence interval. Log-rank test was performed to compare equality of survivor function of subgroups. Cumulative incidence function of reoperation was performed with Nelson-Aalen cumulative hazard estimates. Only the first re-event for each patient during the study was used for analysis. Cox regression was used to detect the risk factors for death and reoperation of any cause reporting hazard ratio (HR) and 95\% confidence interval (Cl). The age between 65 to 70 was set as reference for age related cox analysis. The same applies to prosthesis size 25 in respect to valve size related cox analysis. A $P$-value of $<0.05$ was considered significant. All statistical analyses were performed with the use of STATA software, version 15.

\section{Results}

We included 1604 patients who received a solitary SAVR with CE-P bioprosthesis between November 1999 and November 2015, with a total follow-up of 11.386 patient-years (median follow-up: 7.1 years).

\section{Baseline and operative characteristics}

Table 1 summarize the baseline and operative characteristics. The mean age was 72.7 years; with 19 , $167,285,846$ and 287 patients with the age of $<50,50-65,65-70,70-80$ and $\geq 80$ years, respectively; $61.3 \%$ of the patients were male; AS was the most common aetiology for SAVR $(75.1 \%)$; mean ejection fraction was 53\%; mean EuroSCORE II (ES2) was $1.45 \%$ with a range of $0.5-39.62 \%$; $6.4 \%$ received a size 19 valve; $21.6 \%$ received a size 21 valve; $35.2 \%$ received a size 23 valve; $36.7 \%$ received a size $\geq 25$ valve; and $87.3 \%$ had an EOAI $\geq 0,85$. The mean hospital stay was 8 days (median: 6 days, $n=1520$ ) for all and 10 days for $E S 2 \geq 4 \%$ (median: 8 days).

\section{Early mortality and morbidity}

In-hospital mortality was $2.7 \%(n=43)$ and early ( $\leq 30$ days) mortality at $3.4 \%(n=55)$ in the entire cohort, $3.1 \%$ for low-risk patients (ES2 <4\%) and $11.9 \%$ for ES2 $\geq 4 \%$. The incidence of POAF was observed at $36.4 \%(n=583)$, stroke at $1.3 \%(n=21)$ and for AMI $0.4 \%(n=7)$ with hazard ratio $(H R)$ at $1.03(P=0.70,95 \% \mathrm{Cl}: 0.89-1.20), 1.35(P=0.32,95 \% \mathrm{Cl}: 0.74-2.45)$ and $1.67(P=0.31,95 \% \mathrm{Cl}: 0.63-$ $4.47)$, respectively. The incidence of postoperative treatment (<30 days) with permanent pacemaker or ICD was at $3.9 \%(n=62)$.

\section{Survival}

Figure 2 shows Kaplan-Meier survival plot for the CE-P bioprosthesis. The 1-, 5-, 10- and 15-year survival from all-cause mortality was $93 \%, 77 \%, 52 \%$ and $24 \%$, respectively. The $5-, 10-$, and 15 -year survival for low-risk patients $(n=1545)$ was $78 \%, 52 \%$ and $25 \%$, respectively, and for ES2 $\geq 4, n=59) 63 \%$ and $39 \%$ at 5 and 10 years, respectively. The survival of the matched background population in Denmark was $81 \%$, $57 \%$ and $32 \%$ after $5-, 10$ - and 15 -years, respectively. The survival curve and the matched population were 
significantly different over the 15 years of follow-up $(P<0.05)$. There was great overlap of the two populations with no difference in 10-year survival when censoring all patients with early death $(n=55)$. Survival in relations to age after 10 years was $75 \%, 68 \%, 67 \%, 50 \%$ and $32 \%$ for ages $<50,50-65,65-70$, $70-80$ and $\geq 80$ years, respectively. The 15 -year survival of patients between $50-65$ and $65-70$ was $53 \%$ and $49 \%$, respectively. The 5-, 10 - and 15 -year survival from MACCE-caused mortality was $89 \%, 80 \%$ and $67 \%$, respectively (figure 3). The subgroup survival by ES2 are illustrated in figure 3 (log-rank: $P<0.05$ ) . Figure 4 presents survival according to prosthesis size. Size 25-29 are grouped due to overlap of graphs when estimated separately. Patients implanted with a size 19 had the worst outcome, but since the sample size was only 103 , they were grouped to 19-23. The $1-, 3-, 5-, 10$ - and 15 -year survival for valve 19 23 was $92.4 \%, 85.2 \%, 75.8 \%$ and $21.9 \%$, respectively and for size $25-29,93.2 \%, 86.5 \%, 79.9 \%, 54.9 \%$ and $29.7 \%$, respectively. The median survival in patients with prosthesis sizes $25-29$ was 7.2 years and for size 19-23 it was 7 years, while size 19 was 6.5 years. Using Cox regression analysis of long-term survival (table 2), smoking, age 70-80, age $\geq 80$, and valve size 19-23 were significant risk factors with a HR of $1.59(P<0.01), 1.81(P<0.01), 3.19(P<0.01)$ and $1.22(P=0.03)$, respectively. ES $2<4 \%$ had a HR of 0.61 $(P<0.01)$ while ES2 $\geq 4 \%$ had a HR of $1.64(P<0.01)$. Male gender, diabetes mellitus, prior smoker and valve prosthesis patient mismatch had a HR between 1.07 and 1.22 but were non-significant. Post hoc analysis of lipid-lowering treatment correlated with decreased risk of death the first 10 years (HR: $0.68 ; P<$ 0.01). The cause of death in the cohort was due to MACCE $(36.2 \%, n=273)$; Cancer or tumor $(19.4 \%, n=$ 146); Pulmonary failure $(8.1 \%, n=61)$; Late cerebrovascular disease $(7.7 \%, n=58)$; External cause of injury $(3.4 \%, n=26)$; Miscellaneous $(17 \%, n=128)$; Unknown $(8.2 \%, n=62)$.

\section{Reoperation}

The risk of reoperation with a new CE-P or TAVR of any cause during the follow-up was $4 \%(n=64)$ and $22 \%(n=14)$ was due to endocarditis. The cumulative incidence of reoperation according to prosthesis

size are presented in figure 5 and table 3 . The risk of reoperation for all prosthesis sizes after 5,10 and 15 years was $1.3 \%, 5 \%$ and $13.3 \%$, respectively. Cox regression analysis of reoperation indicated that age $<50$, age 50-65, and VP-PM was a significant risk factor (HR: 5.61, P<0.01, HR: 2.44, P< 0.02, HR: 2.19, P $=0.01$, respectively), and ES2 $<4 \%$ was significant correlated with lower risk (HR: $0.12, P<0.01)$. ES2 $\geq$ $4 \%$ was significantly correlated with a higher risk of reoperation (HR: $8.6, P<0,01)$.

\section{Discussion}

This 15-year multi-centre observational follow-up study evaluated the long-term survival after SAVR with CE-P valve in terms of mortality and clinical outcomes in 1604 Danish patients having a solitary SAVR. Our study found a 30 -day all-cause mortality at 3.4\%, and a 5 -, 10- and 15-year survival from all-cause at $77 \%, 52 \%$ and $24 \%$, respectively including a 7.5 -year risk of reoperation $<5 \%$.

This study's observation of all-cause mortality was consistent with the Danish matched population after early risk and until year 10 , were the mortality takes another discrete yet noticeable hit until the end of the follow-up (figure 2). The early mortality was higher than predicted in comparison to mean ES2 of the 
population (meanES2: 1.45\%, predicted number of deaths: 23). After patients surpass the general risk of the operation the first 30 days, the survival rate matches to the Danish population for 10 years. We may assume that the CE-P valves durability is being challenged by this point, which can also be supported by literature describing the development of SVD in CE-P at $9.24 \%$ after 10 years (10), and 18\% after 15 years (7). The Danish population is matched according to the mean age of our baseline (72.7 years) which matches previous reports $(3,7-9,19,21,22)$, including $12 \%<65$ years. Even though younger age and small valve sizes are associated with accelerated development of SVD $(1,3,6,8-10)$, table 2 shows that age $<65$ years is significantly associated with reoperation, and not with death. The opposite goes for valve size 19-23. [Vahanian, 2013, [Guidelines on the management of valvular heart disease (version 2012). The Joint Task Force on the Management of Valvular Heart Disease of the European Society of Cardiology (ESC) and the European Association for Cardio-Thoracic Surgery (EACTS) ]Furthermore, reoperation has a HR of death at $1.07(P=0.75)$. However, older demographics ( $\geq 70$ years) have a significant increased risk of death and decreased risk of reoperation (table 2). This may suggest that ether the durability of the CE-P valve is not the primary cause of death in this age group, or and more likely that they're not suitable for reoperation because of development and progress of comorbidities. Furthermore, that the increased risk in mortality in small vales is presumable explained by the demographics rather than SVD development. Nevertheless, our findings could indicate that patients undergoing SAVR with CE-P can expect a survival matching the background population the next 10 years after overcoming early risks. A Danish study described the 10-year survival from all-cause mortality of CE$P$ at $36 \%$ resulting, which is significantly worse than our findings of $52 \%$ for roughly the same period (19). This could be explained by their single-centre approach, their inclusion of concomitant CABG procedures and the fact that we conducted our results November 2018 which prolongs our follow-up with 4.5 years. The surgical technique and postprocedural medical attention have improved tremendously over time, and therefore a prolonged period of 4.5 years will have a significant effect on a 10-year measurement. Additionally, we may assume that if patients are eligible for concomitant CABG, they have increased probability of comorbidity contributing to the risk of death. It does however interfere with their true longterm survival analysis and durability of the CE-P valve. It is noteworthy that our survival is consistent with other studies; overall 5-, 10- and 15-year survival rate in China (81.58 \% 66.19\% and 57.33\% (10)), overall 10 - and 15 -year survival rate in France $(52.4 \%$ and $31.1 \%(9))$, overall 5 -, 10 - and 15 -year survival rate in a Canadian study $(78 \%, 55 \%$ and $34 \%(21))$ and others (23). We also investigated the survival from MACCEcause mortality in order to more comprehensive describe the valve durability in combination with all causes of late death (figure 3 ). The cause of late death was $55.6 \%$ due to other than valve or MACCErelated causes, why one might argue that CE-P surpasses the general patient's life expectancy and therefore making it a reliable choice for SAVR and that future randomized studies could take MACCE into account when evaluating the durability in order to give a more widespread evaluation of the valves. VPPM (HR: 2.19) and high-risk patients (HR: 6.62) had a significant impact on the risk of reoperation, while valve size was not an independent risk factor. VP-PM's impact on reoperation contradicts earlier report of CE-P using calculated EOA reference values to predict VP-PM, which were substantially higher than the values provided by the manufacture (24). The prediction of VP-PM is controversial because of various calculations, but one study comparing 4 methods argued that the best calculations are made by EOA 
measured in vivo by Doppler echocardiography (25). The latest meta-analysis supported the association of VP-PM have higher risk for perioperative, 1-, 5- and 10-year mortality rates in comparison to those with non-significant or no VP-PM. In our study, $12.7 \%$ had EOAI $<0.85$ why this could contribute to MACCEcause mortality, though our estimates are based on manufactural EOA measurements indexed with BSA. ES2 $\geq 4 \%$ were found as an independent risk factor for reoperation, which correlates with the selectionbias in this group. Patients with ES2 $\geq 4 \%$ have more comorbidities such as renal failure, previous AMI, COPD, poor lung capacity, endocarditis or the need of acute need of operation. This could also explain the prolonged hospital stay in high risk compared with low risk. The small valve sizes were not associated with reoperation, which may be explained by unsuitability for surgery or the small sample size. The operative risk of reoperation due to SVD in CE-P was earlier described at $0 \%$ for size 19 and 21 and $0.1 \%$ for all valve sizes (19), which may support our non-correlation of small valves with reoperation. However, the only way to finally evaluate whether a correlation between small valves and the development of SVD is present, is by performing a prospective study with close echocardiographic follow-up, so no patient would experience SVD without notice. The cumulative incidence function of reoperation due to any cause was $<5 \%$ after 7.5 years (figure 5 ), which is higher than previous studies reporting freedom of reoperation at $96 \%-99.5 \%$ after 10 years $(19,21,26)$. This could be due to our broad range of age (20-91 years) (21). Forcillo et al. divided their population into 3 different age-categories illustrating that younger patients had a higher risk of reoperation with a 10 -year risk of $90 \%$ in $<60$ years of age with no mention of the subgroup size (21), and Langanay et al. had an age range of 80-96 years(26). The small sample size after 7.5 years inhibits further associations to be made. Other clinical implications such as stroke, AMI, permanent pacemaker or ICD and POAF is at focus, especially in the comparison to TAVR. We observed a 30-days stroke rate at 1.3\% (21 patients; HR:1.35; Cl:0.74-2.45; $P=0.32$ ) being lower than the SAVR findings in the PARTNER 3 trail which was 2.4\% (meanES2: 1.5\%) (20). The 30-day incidence of AMI was also lower in our study $(0.4 \%)$ compared to literature $(1.3-1.6 \%)(20,27)$. Lower incidence was also found regarding pacemaker or ICD implantation (3.9\%), as SAVR-reports once again reports higher incidences (4.1-7.4\% - only pacemaker only) $(20,27,28)$. Interestingly, our data matches in general the findings found in another CE-P valves cohort study (stroke 1\%, AMI 1\%, atrioventricular-block $4 \%(21)$ ). The incidence of POAF $(36.4 \%)$ is however higher than some reports (11\%) (27), which might be due to the definition of POAF in regards to duration and the overall awareness in the ward, since it is comparable to other findings $(32 \%-39.5 \%)(20,29)$.

This research was limited by its retrospective design and the absence of continuance echocardiographic evaluation of $\operatorname{SVD}(6,30)$. Long-term SVD and its relations to long-term survival therefore still remains in question. Furthermore, of the 1604 patients, 754 died before this study was conducted, and postoperative evaluation of SVD would not have been possible and $8.2 \%$ of cause of death remains uncertain. Additionally, the cohort was database-dependent and therefore relays on correct SKS codes, though earlier studies of the WDHD have shown very good quality evaluation with errors lower than $3 \%(31)$. Selection bias in this study was minimized by the universal health care system based on the Beveridge model. 


\section{Conclusion}

We cautiously conclude that our findings match previous literature, and that CE-P is a well-tested valve with satisfying long-term durability, which do not affect the long-term survival seriously for patients undergoing aortic valve replacement. This support the idea for future comparative research of TAVRvalves may be randomized solely against Carpentier-Edwards Perimount, and not pooled with other inferior bioprosthetic valves (3).

\section{Abbreviations}

AS: Aortic stenosis; AVR: Aortic valve replacement; BSA: Body surface area; CE-P: Carpentier-Edwards Perimount; Cl: Confidence interval; EOA: Effective orifice area; EOAl: Effective orifice area index; ES2: EuroSCORE II; HR: Hazard ratio; MACCE: Major adverse cardiovascular and cerebral events; POAF: Postoperative atrial fibrillation; SVD: Structural valve deterioration; SAVR: Surgical aortic valve replacement; TAVR: Transcatheter aortic-valve replacement; VP-PM: Valve patient-prothesis mismatch; WDHR: Western Danish Heart Registry.

\section{Declarations}

\section{Ethics approval and consent to participate}

This registry-based study was ethically approved by the ethics committee, Region Southern Denmark Data Protection Agency, Odense, Denmark.

\section{Consent for publication}

Not applicable.

\section{Availability of data and materials}

The datasets used and/or analysed during the current study are available from the corresponding author on reasonable request.

\section{Competing interests}

The authors declare no conflict of interest.

\section{Funding}

This research received no grants from any funding agency in commercial, the public, or not-for-profit sectors.

\section{Authors' contributions}

LK and LR initiated and led the study, organized data collection and carried 
out the statistical analyses as well as drafting of the manuscript. MK wrote parts of the manuscript,

and contributed to the study design. All authors revised the manuscript critically and and approved the content of the final manuscript.

\section{Acknowledgements}

Not applicable.

\section{References}

1. Baumgartner H, Falk V, Bax JJ, De Bonis M, Hamm C, Holm PJ, et al. 2017 ESC/EACTS Guidelines for the management of valvular heart disease. Eur Heart J. 2017;38(36):2739-91.

2. Kirmani BH, Jones SG, Malaisrie SC, Chung DA, Williams RJ. Limited versus full sternotomy for aortic valve replacement. Cochrane Database Syst Rev. 2017;4:Cd011793.

3. Issa IF, Poulsen SH, Waziri F, Torp Pedersen C, Nielsen PH, Riber L, et al. Structural valve deterioration in the Mitroflow biological heart valve prosthesis. Eur J Cardiothorac Surg. 2018;53(1):136-42.

4. Hulin A, Hego A, Lancellotti P, Oury C. Advances in Pathophysiology of Calcific Aortic Valve Disease Propose Novel Molecular Therapeutic Targets. Front Cardiovasc Med. 2018;5:21.

5. Rahimtoola SH. Choice of prosthetic heart valve in adults an update. J Am Coll Cardiol. 2010;55(22):2413-26.

6. Capodanno D, Petronio AS, Prendergast B, Eltchaninoff H, Vahanian A, Modine T, et al. Standardized definitions of structural deterioration and valve failure in assessing long-term durability of transcatheter and surgical aortic bioprosthetic valves: a consensus statement from the European Association of Percutaneous Cardiovascular Interventions (EAPCI) endorsed by the European Society of Cardiology (ESC) and the European Association for Cardio-Thoracic Surgery (EACTS). Eur Heart J. 2017;38(45):3382-90.

7. McClure RS, Narayanasamy N, Wiegerinck E, Lipsitz S, Maloney A, Byrne JG, et al. Late outcomes for aortic valve replacement with the Carpentier-Edwards pericardial bioprosthesis: up to 17-year followup in 1,000 patients. Ann Thorac Surg. 2010;89(5):1410-6.

8. Johnston DR, Soltesz EG, Vakil N, Rajeswaran J, Roselli EE, Sabik JF 3. Long-term durability of bioprosthetic aortic valves: implications from 12,569 implants. Ann Thorac Surg. 2015;99(4):123947. rd, et al.

9. Bourguignon T, Bouquiaux-Stablo AL, Candolfi P, Mirza A, Loardi C, May MA, et al. Very long-term outcomes of the Carpentier-Edwards Perimount valve in aortic position. Ann Thorac Surg. 2015;99(3):831-7.

10. Guo H, Lu C, Huang H, Xie B, Liu J, Zheng S, et al. Long-Term Clinical Outcomes of the CarpentierEdwards Perimount Pericardial Bioprosthesis in Chinese Patients with Single or Multiple Valve Replacement in Aortic, Mitral, or Tricuspid Positions. Cardiology. 2017;138(2):97-106. 
11. Sohn SH, Jang MJ, Hwang HY, Kim KH. Rapid deployment or sutureless versus conventional bioprosthetic aortic valve replacement: A meta-analysis. J Thorac Cardiovasc Surg. 2018.

12. Conte JV, Hermiller J Jr, Resar JR, Deeb GM, Gleason TG, Adams DH, et al. Complications After Selfexpanding Transcatheter or Surgical Aortic Valve Replacement. Semin Thorac Cardiovasc Surg. 2017;29(3):321-30.

13. Baumbach H, Ahad S, Rustenbach C, Hill S, Schaufele T, Wachter K, et al. Conventional versus Transapical Aortic Valve Replacement: Is It Time for Shift in Indications? Thorac Cardiovasc Surg. 2017;65(3):212-7.

14. Cao C, Ang SC, Indraratna P, Manganas C, Bannon P, Black D, et al. Systematic review and metaanalysis of transcatheter aortic valve implantation versus surgical aortic valve replacement for severe aortic stenosis. Ann Cardiothorac Surg. 2013;2(1):10-23.

15. Motloch LJ, Reda S, Rottlaender D, Khatib R, Muller-Ehmsen J, Seck C, et al. Postprocedural atrial fibrillation after transcatheter aortic valve implantation versus surgical aortic valve replacement. Ann Thorac Surg. 2012;93(1):124-31.

16. Maesen B, Nijs J, Maessen J, Allessie M, Schotten U. Post-operative atrial fibrillation: a maze of mechanisms. Europace. 2012;14(2):159-74.

17. Pivatto Junior F, Teixeira Filho GF, Sant'anna JR, Py PM, Prates PR, Nesralla IA, et al. Advanced age and incidence of atrial fibrillation in the postoperative period of aortic valve replacement. Rev Bras Cir Cardiovasc. 2014;29(1):45-50.

18. Frendl G, Sodickson AC, Chung MK, Waldo AL, Gersh BJ, Tisdale JE, et al. 2014 AATS guidelines for the prevention and management of perioperative atrial fibrillation and flutter for thoracic surgical procedures. J Thorac Cardiovasc Surg. 2014;148(3):e153-93.

19. Nielsen PH, Hjortdal V, Modrau IS, Jensen H, Kimose HH, Terp K, et al. Durability after aortic valve replacement with the Mitroflow versus the Perimount pericardial bioprosthesis: a single-centre experience in 2393 patients. Eur J Cardiothorac Surg. 2016;49(6):1705-10.

20. Mack MJ, Leon MB, Thourani VH, Makkar R, Kodali SK, Russo M, et al. Transcatheter Aortic-Valve Replacement with a Balloon-Expandable Valve in Low-Risk Patients. N Engl J Med. 2019;380(18):1695-705.

21. Forcillo J, Pellerin M, Perrault LP, Cartier R, Bouchard D, Demers P, et al. Carpentier-Edwards pericardial valve in the aortic position: 25-years experience. Ann Thorac Surg. 2013;96(2):486-93.

22. Webb J, Parkin D, Tondel K, Simitsis P, Roxburgh J, Chambers JB. A comparison of early redo surgery rates in Mosaic porcine and Perimount bovine pericardial valves. Eur $\mathrm{J}$ Cardiothorac Surg. 2018;54(4):724-8.

23. Chang HW, Kim WS, Ahn JH, Carriere KC, Jeong DS, Cho YH, et al. Late clinical outcomes of aortic valve replacement with Carpentier-Edwards pericardial valves. J Thorac Dis. 2019;11(12):5372-81.

24. Flameng W, Meuris B, Herijgers P, Herregods MC. Prosthesis-patient mismatch is not clinically relevant in aortic valve replacement using the Carpentier-Edwards Perimount valve. Ann Thorac Surg. 2006;82(2):530-6. 
25. Bleiziffer S, Eichinger WB, Hettich I, Guenzinger R, Ruzicka D, Bauernschmitt R, et al. Prediction of valve prosthesis-patient mismatch prior to aortic valve replacement: which is the best method? Heart. 2007;93(5):615-20.

26. Langanay T, Rouze S, Tomasi J, Aymami M, Rehman SM, Anselmi A, et al. Conventional aortic valve replacement in 2005 elderly patients: a 32-year experience. Eur J Cardiothorac Surg. 2018.

27. Thourani VH, Forcillo J, Szeto WY, Kodali SK, Blackstone EH, Lowry AM, et al. Outcomes in 937 Intermediate-Risk Patients Undergoing Surgical Aortic Valve Replacement in PARTNER-2A. Ann Thorac Surg. 2018;105(5):1322-9.

28. Chen S, Redfors B, Ben-Yehuda O, Crowley A, Greason KL, Alu MC, et al. Transcatheter Versus Surgical Aortic Valve Replacement in Patients With Prior Cardiac Surgery in the Randomized PARTNER 2A Trial. JACC Cardiovasc Interv. 2018;11(21):2207-16.

29. Zebis LR, Christensen TD, Thomsen HF, Mikkelsen MM, Folkersen L, Sorensen HT, et al. Practical regimen for amiodarone use in preventing postoperative atrial fibrillation. Ann Thorac Surg. 2007;83(4):1326-31.

30. Dvir D, Bourguignon T, Otto CM, Hahn RT, Rosenhek R, Webb JG, et al. Standardized Definition of Structural Valve Degeneration for Surgical and Transcatheter Bioprosthetic Aortic Valves. Circulation. 2018;137(4):388-99.

31. Rasmussen LA, Botker HE, Jensen LO, Ravkilde J, Riber L, Nielsen PH, et al. Quality assurance of the Western Denmark Heart Registry, a population-based healthcare register. Dan Med J. 2017;64(10).

\section{Tables}


Table 1

Preoperative baseline characteristics of patients undergoing solitary SAVR with CE-Perimount bioprosthesis.

\begin{tabular}{|c|c|}
\hline Patients, $\mathrm{n}$ & 1604 \\
\hline Male, n (\%) & $984(61.3 \%)$ \\
\hline \multicolumn{2}{|l|}{ Age } \\
\hline Mean, years (Range) & $72.7(20-91)$ \\
\hline \multicolumn{2}{|l|}{ Etiology, n (\%) } \\
\hline Aortic Stenosis & $1204(75.1 \%)$ \\
\hline Aortic Insufficience & $248(15.5 \%)$ \\
\hline Stenosis and Insufficience & $7(0.4 \%)$ \\
\hline Endocarditis & $30(1.9 \%)$ \\
\hline Others incl. missing & $115(7.2 \%)$ \\
\hline \multicolumn{2}{|l|}{ Valve size, $n=1601(\%)$} \\
\hline $19 \mathrm{~mm}$ & $103(6.4 \%)$ \\
\hline $21 \mathrm{~mm}$ & $346(21.6 \%)$ \\
\hline $23 \mathrm{~mm}$ & $564(35.2 \%)$ \\
\hline $25 \mathrm{~mm}$ & $412(25.7 \%)$ \\
\hline $27 \mathrm{~mm}$ & $156(9.7 \%)$ \\
\hline $29 \mathrm{~mm}$ & $20(1.3 \%)$ \\
\hline $\mathrm{EOAI} \geq 0,85(\%), \mathrm{n}=1483$ & $1295(87.3 \%)$ \\
\hline \multicolumn{2}{|l|}{ Ejection Fraction, $n=1469$} \\
\hline Mean \% $(95 \% \mathrm{Cl})$ & $53(52.55-53.89)$ \\
\hline Range & $0-92$ \\
\hline \multicolumn{2}{|l|}{ Smoking, $n=1473$} \\
\hline Active smoker & $237(14.8 \%)$ \\
\hline Non-smoker & $524(32.8 \%)$ \\
\hline Previous smoker & $712(44.6 \%)$ \\
\hline EuroSCORE II, $n=1604$ & \\
\hline
\end{tabular}




\begin{tabular}{|ll|}
\hline Patients, $\mathrm{n}$ & 1604 \\
\hline Mean \pm SD $(95 \% \mathrm{Cl})$ & $1.45 \pm 2.08(1.35-1.55)$ \\
\hline Range, score & $0.5-39.62$ \\
\hline Diabetes mellitus, $\mathrm{n}=1561(\%)$ & $204(13.1 \%)$ \\
\hline Previous AMl, $\mathrm{n}=1557(\%)$ & $119(7.6 \%)$ \\
\hline Previous PCl, $\mathrm{n}=1555(\%)$ & $110(7.1 \%)$ \\
\hline Lipid-lowering treatment, $\mathrm{n}=1538(\%)$ & $707(46 \%)$ \\
\hline Hypertension treatment, $\mathrm{n}=1528(\%)$ & $873(57.1 \%)$ \\
\hline Previous Operations, $\mathrm{n}=1602(\%)$ & \\
\hline 0 & $1476(92.1 \%)$ \\
\hline Previois aortic valve operation & $11(0.7 \%)$ \\
\hline Other heart surgery & $39(2.4 \%)$ \\
\hline BSA, $\mathrm{n}=1486$ & \\
\hline Mean \pm SD, $\mathrm{m}^{2}$ (95\% Cl) & $1.89 \pm 0.2(1.88-1.90)$ \\
\hline Range, $\mathrm{m}^{2}$ & $1.34-2.67$ \\
\hline EOAl: effective orifice area index; BSA: Body surface area \\
\hline
\end{tabular}


Table 2

Cox regression analysis of death and reoperation.

\begin{tabular}{|c|c|c|c|c|}
\hline & Death & & Reoperation & \\
\hline & $\begin{array}{l}\text { Hazard Ratio (95\% } \\
\text { Cl) }\end{array}$ & $\begin{array}{l}\mathrm{P}- \\
\text { value }\end{array}$ & $\begin{array}{l}\text { Hazard Ratio (95\% } \\
\text { Cl) }\end{array}$ & $\begin{array}{l}\mathrm{P}- \\
\text { value }\end{array}$ \\
\hline Male gender & $1.07(0.92-1.24)$ & 0.360 & $1.56(0.91-2.66)$ & 0.107 \\
\hline \multicolumn{5}{|l|}{ Age group ${ }^{\star \star}$} \\
\hline $65-70$ & 1.0 & & 1.0 & \\
\hline$<50$ & $\begin{array}{l}1.35(0.55- \\
3.33)\end{array}$ & 0.516 & $\begin{array}{l}5.61(1.59- \\
19.8)\end{array}$ & $0.007 *$ \\
\hline $50-65$ & $\begin{array}{l}1.05(0.74- \\
1.51)\end{array}$ & 0.77 & $\begin{array}{l}2.44(1.17- \\
5.08)\end{array}$ & $0.017 *$ \\
\hline $70-80$ & $\begin{array}{l}1.81(1.43- \\
2.28)\end{array}$ & $<.001 *$ & $\begin{array}{l}0.71(0.37- \\
1.38)\end{array}$ & 0.312 \\
\hline$\geq 80$ & $\begin{array}{l}3.19(2.46- \\
4.12)\end{array}$ & <. 001 * & $\begin{array}{l}0.60(0.21- \\
1.70)\end{array}$ & 0.337 \\
\hline Reoperation $* \star \star$ & $\begin{array}{l}1.06(0.74- \\
1.52)\end{array}$ & 0.747 & & \\
\hline \multicolumn{5}{|l|}{ Valve size } \\
\hline 25 & 1.0 & & 1.0 & \\
\hline $19-23$ & $1.22(1.03-1.45)$ & $0.025^{\star}$ & $0.73(0.42-1.26)$ & 0.252 \\
\hline $27-29$ & $0.94(0.71-1.25)$ & 0.658 & $1.03(0.45-2.34)$ & 0.948 \\
\hline Diabetes Mellitus & $1.22(0.99-1.51)$ & $0.067^{\star}$ & $1.38(0.68-2.81)$ & 0.369 \\
\hline Smoker & $1.59(1.29-1.97)$ & $<0.001 *$ & $1.61(0.74-3.52)$ & 0.234 \\
\hline Previous smoker & $1.08(0.91-1.28)$ & 0.383 & $1.39(0.77-2.51)$ & 0.269 \\
\hline VP-PM & $1.18(0.95-1.48)$ & 0.144 & $2.19(1.21-3.98)$ & $0.010 *$ \\
\hline EuroSCORE II < 4\% & $0.61(0.43-0.87)$ & $0.006^{*}$ & $0.12(0.06-0.22)$ & $<.001 *$ \\
\hline Hypertension treatment & $1.01(0.87-1.17)$ & 0.889 & $0.98(0.59-1.64)$ & 0.945 \\
\hline $\begin{array}{l}\text { Lipid-lowering } \\
\text { treatment } \star \star \star \star\end{array}$ & $0.68(0.58-0.80)$ & ${ }_{0.001 *}$ & $1.09(0.61-1.96)$ & 0.759 \\
\hline
\end{tabular}


VP-PM: Valve prosthesis-patient mismatch. ${ }^{*} \mathrm{P}<0.05$

**Age groups for reoperation are sorted by the age of the primary CE-P procedure.

*** Reoperation after primary AVR with another CE-P or TAVR

${ }^{\star * * *}$ Cox regression of the first 10 years.

Table 3

Cumulative incidence function of reoperation.

\begin{tabular}{|c|c|c|c|c|c|}
\hline $\begin{array}{l}\text { Prosthesis } \\
\text { size }\end{array}$ & $\begin{array}{l}\mathrm{CIF}(95 \% \mathrm{Cl}) \text { at } \\
\text { year } 1\end{array}$ & $\begin{array}{l}\mathrm{CIF}(95 \% \mathrm{Cl}) \text { at } \\
\text { year } 5\end{array}$ & $\begin{array}{l}\text { CIF }(95 \% \mathrm{Cl}) \\
\text { at } \\
\text { year } 7,5\end{array}$ & $\begin{array}{l}\text { CIF }(95 \% \mathrm{Cl}) \\
\text { at } \\
\text { year } 10\end{array}$ & $\begin{array}{l}\text { CIF }(95 \% \mathrm{Cl}) \\
\text { at } \\
\text { year } 15\end{array}$ \\
\hline $23-29$ & $0.9 \%(0.5-1.7)$ & $1.49 \%(0.9-2.4)$ & $\begin{array}{l}3.19 \%(2.0- \\
4.6)\end{array}$ & $\begin{array}{l}5.0 \%(3.5- \\
7.1)\end{array}$ & $\begin{array}{l}15 \%(9.7- \\
22.9)\end{array}$ \\
\hline 21 & $0,3 \%(0.04-2.1)$ & $0.6 \%(0.2-2.0)$ & $\begin{array}{l}3.1 \%(1.5- \\
6.5)\end{array}$ & $\begin{array}{l}4.5 \%(2.3- \\
8.7)\end{array}$ & $\begin{array}{l}7.7 \%(3.1- \\
18.2)\end{array}$ \\
\hline 19 & $0,97 \%(0,1-6,7)$ & $2,12 \%(0,5-8.3)$ & $\begin{array}{l}4,25 \%(1.3- \\
13.5)\end{array}$ & $\begin{array}{l}6,64 \%(2.4- \\
17.8)\end{array}$ & $\begin{array}{l}14.42 \%(4.6- \\
40.1)\end{array}$ \\
\hline All & $0.78 \%(0.4-1.4)$ & $1.34 \%(0.9 .-2.1)$ & $\begin{array}{l}3.24 \%(2.3- \\
4.5)\end{array}$ & $\begin{array}{l}5.0 \%(3.7- \\
6.8)\end{array}$ & $\begin{array}{l}13,3 \%(9.2- \\
19.2)\end{array}$ \\
\hline
\end{tabular}

Figures 


\section{3 patients from WDHR}

\section{6 dublicates}

\section{7 patients}

\section{3 invalid patients}

1604 patients with solitary AVR with

CE-Perimount bioprosthetic from

1999 to 2015

Figure 1

Flow chart of study population selection. WDHR, Western Danish Heart Registry; AVR, aortic valve replacement; CE-Perimount, Carpentier-Edwards Perimount 


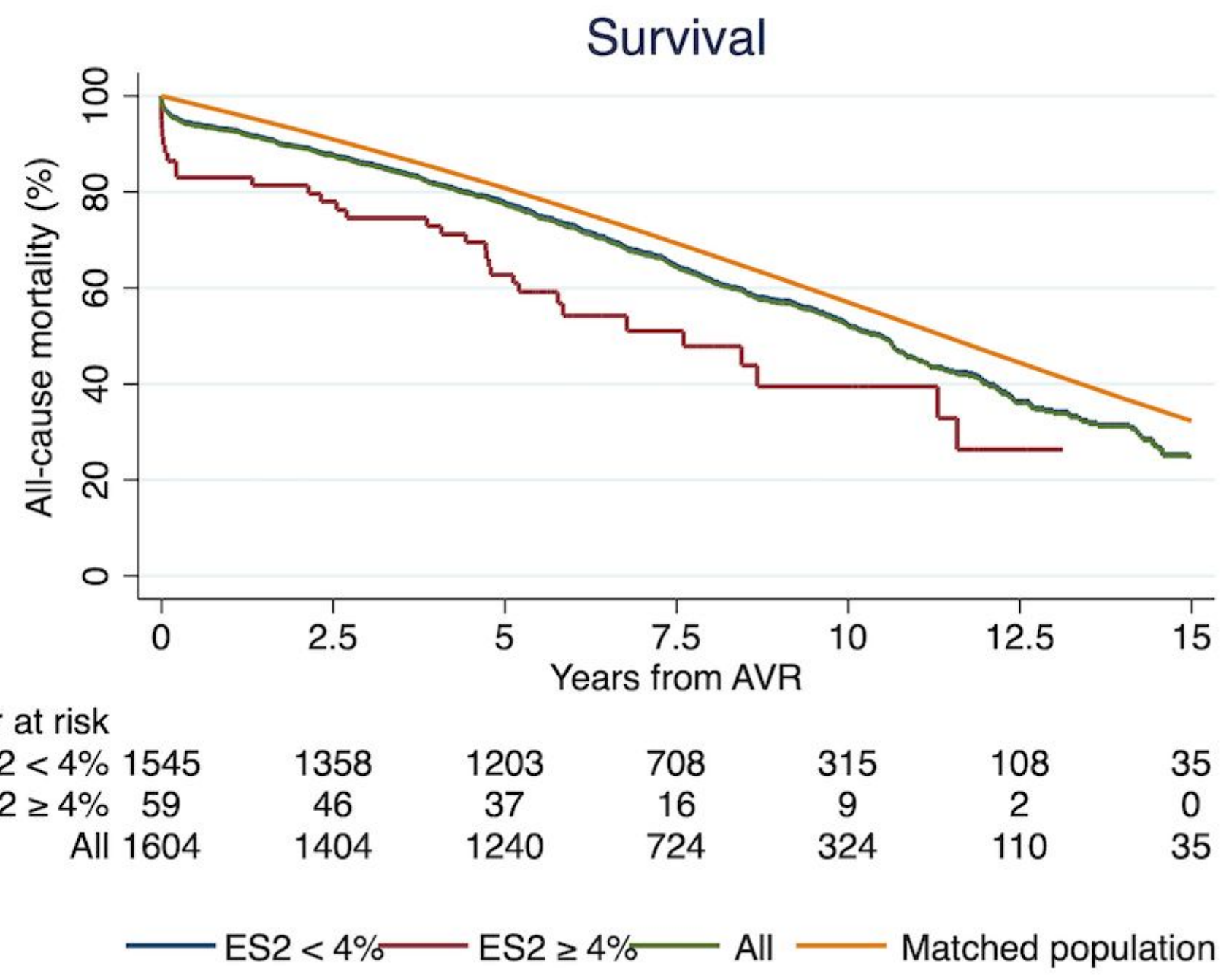

Figure 2

Overall patient survival after aortic valve replacement (green line) compared with normal Danish population (orange line) and according to EuroSCORE II (ES2). 


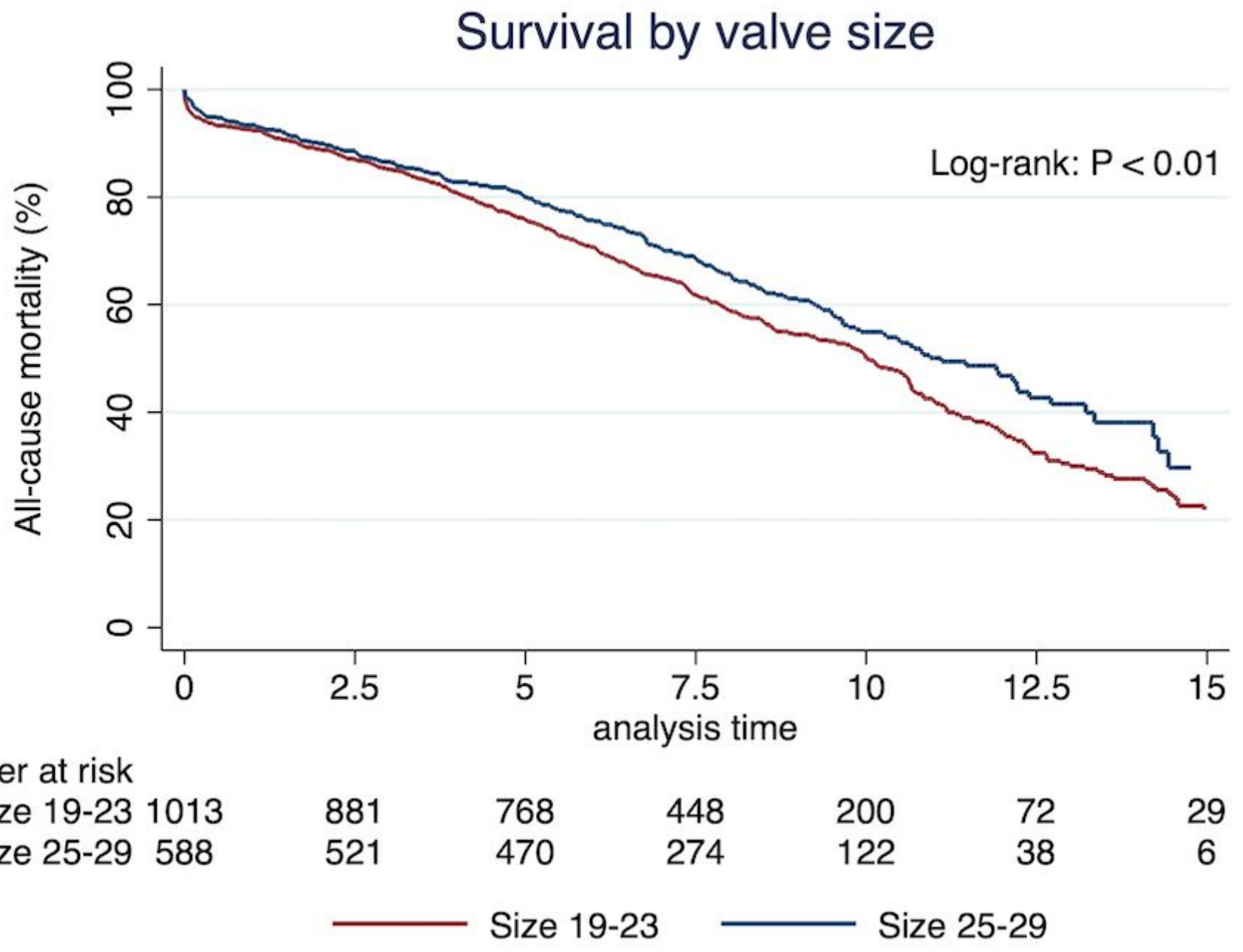

Figure 4

Overall survival according to prosthesis sizes 19-23 (red) and 25-29 (blue). 


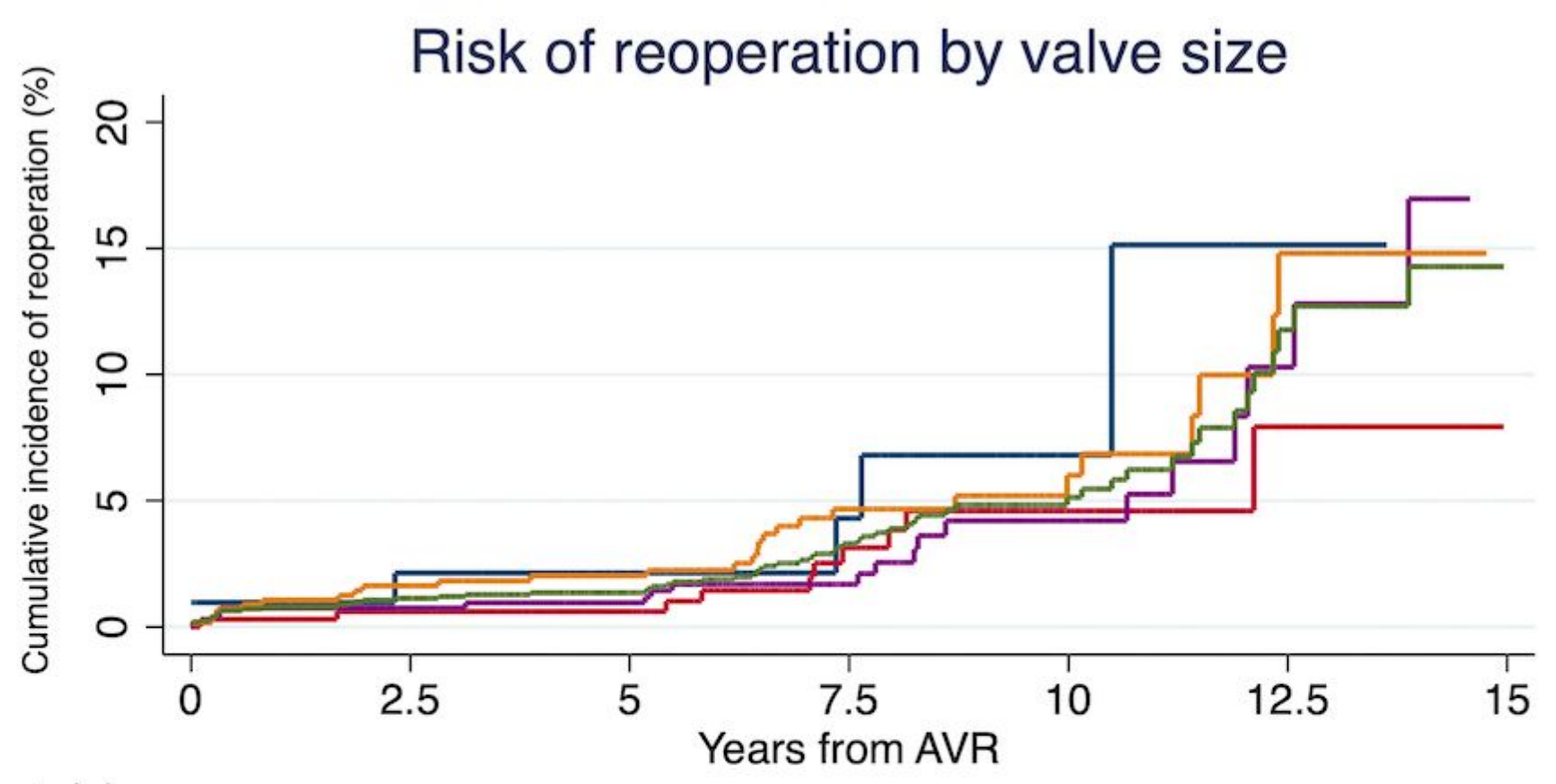

Number at risk

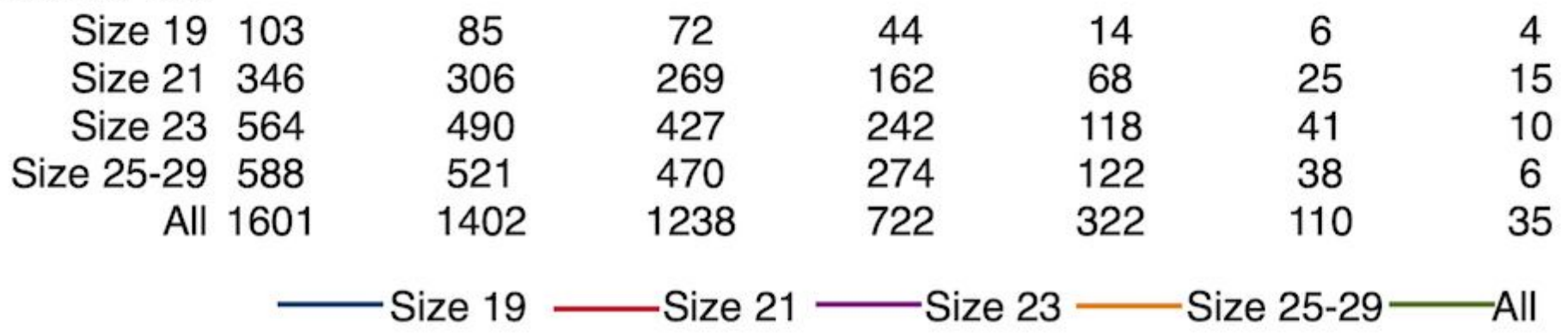

Figure 5

Cumulative incidence of reoperation according to prosthesis size. 